\title{
DAVID BALLANTYNE
}

Centre for Services Management Cranfield School of Management Cranfield Institute of Technology Cranfield, Bedford MK43 OAL

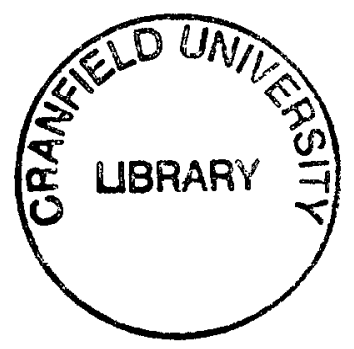

$-$

(Tel 0234 - 751122) 


\title{
TURNING THE WHEEL OF QUALITY IMPROVEMENT - CONTINUOUSLY
}

\author{
David Ballantyne \\ Centre for Services Management \\ Cranfield School of Management, UK
}

\section{INTRODUCTION}

Quality improvement, which has its expression in marketing as customer service improvement, is being fuelled by new technology (information and delivery systems) and competitive action under open market conditions (deregulation). These 'revolutionary' events are inter-related and have fused together as one rolling, cascading event, invading all financial services markets, giving focus and a new meaning to service quality management (Ballantyne, 1987).

In exploring the methods and pathways for 'turning the wheel of quality improvement - continuously', it is assumed that planning for quality improvement has the support of top management as a strategic initiative, and that the argument has been won in favour of quality as a sustainable competitive advantage (Peters, 1989, p 488 and Porter, 1985).

In this paper, the interdependence of staff motivation, performance measurement, and rewards will be stressed. Turning the wheel of quality improvement involves designing a good fit for these elements within the programme framework, and reassessing the historic role of managers in the planning, organising and controlling processes. 


\section{PRISONERS OF THE PROCESS}

All work is process. No matter what we do at work we are involved in processes. Sets of processes are connected as performance 'systems'. We are enmeshed in systems and processes in financial services as much as a worker in charge of a metal press, or an airline pilot.

One of the remarkable features of the management philosophy known as Total Quality Management (TQM) is the way in which it has drawn us to a new understanding of the relationship between the performance systems, staff, and customers (Deming, 1982 and Juran, 1980).

TQM is 'total', because it is concerned with all work processes and the way they connect with customer needs, no matter whether they are tightly specified or of ten in the case of banking and financial services, rather imprecisely specified. And what is it that customers expect? Each organisation needs to know its own critical service issues, nevertheless research evidence enables us to identify five overall dimensions of service performance. These are: reliability, responsiveness, (re)assurance, empathy, and tangible evidence of service, that is, the physical cues to the nature of the service itself (Berry, Bennett and Brown, 1989, p 26).

The service challenge to front line staff is immense. What is often not understood is that 'reliability' and 'responsiveness' of staff are dependent upon the reliability and responsiveness of the technological support. We may all 'do our best' but in overall delivery of quality service, we are 'prisoners of the process'*. It is the performance of the total system that must therefore be the object of analysis for quality improvement.

* 'Prisoner of the proceas' is a term used in a speech by Bruce Irwin, Executive Director, Total Quality Management Institute of Australis, November 1987. 
Deming, Juran and others have found that the overwhelming bulk of the variation in the outcomes of processes can be attributed to the way the processes are designed to operate and are maintained. Invariably, they found that the process is the villain, not the worker. The issue here is the configuration of policies, premises, procedures, machines and programmes which support (or otherwise) the quality of work performance. In this context the design of individual jobs is also a 'process issue'. Yet as a rule when something goes wrong, we look to the person 'responsible', rather than look for a failure in the process design.

There is more yet. Customers of ten attribute the quality of their service experience to the performance of service staff. This is a natural enough perception but nonetheless an invalid observation; what customers really experience is some part of the performance system of which staff are the agents.

Banking and retail financial services especially are at the crossroads. Deregulation puts the customer in a new focus, as the reference point for the management of work. Managerial knowledge, the knowledge of accumulated experience, is insufficient. What needs to happen to start the wheel of quality turning comes down to knowledge generation and knowledge sharing. Restore pride of workmanship, Deming would say.

\section{PURIFICATION OF EFFORT}

The 19th century craftsperson knew his or her skill well. It was developed over time through the sweat of action, observation and imitation. Knowledge by action, that is to 'act-on' resources. Such 'know how' was an integration of many things. With diversity, complexity and size, came the 'routinisation' of work, the splintering and 
channelling of knowledge and skills, with 'efficiency' as the driving force and the pathway to profit. This has been aptly called the 'purification of effort' in the management of work (Zuboff, 1988, p 40).

What has been gained is considerable, but what has been lost is the craftsperson's integration of work knowledge and the ability to 'act-on'. Knowledge is associated with the role of the manager who has become responsible for analysing and organising work tasks, planning and controlling the outputs.

The 'purification of effort' was central to the agenda of the proponents of scientific management. Among the first and certainly the most famous was Frederick Taylor (1856-1917). His focus was improved task design with assessment by 'expert' time studies, and later, time and motion studies. Taylor insisted that it was management's responsibility to organise control and design work, tasks and activities, so that workers could perform more efficiently (Kakabadse, Ludlow and Vinnicombe, 1988, pp 12-13). And so 'purification of effort' builds more and more control mechanisms focused to supply managers and planners with data necessary for adjustment of processes and improvement (Zuboff, 1988, pp 42-3).

Many management practices are based on the philosophy of Taylor's ideas, such as work study, payment for performance, management by objectives and incentive payment schemes. Extreme examples of Taylorism are the view that there is absolutely 'one best way' to do any particular work task (and therefore that is the most economic way of proceeding) and that people are motivated almost solely by financial rewards (ignoring the broader range of social effects which impact on motivation and job satisfaction). 
The Achilles' heel of Taylorism, therefore, is that it assumes that all knowledge is legitimised by management, and so data is channelled to managers for their appraisal, diagnosis and decision, each according to their experience. The dilemma for modern management is how to get knowledge (as distinct from the data) to improve or innovate in work practices.

We all become 'prisoners of the process'. We 'act-in' the system. What is required is to 'break-out' of the system and deal with quality improvement ideas separately from quality improvement decisions. This is a simple step in managerial policy but a necessary one. It opens the way for staff at all levels to participate in the improvement of quality by generating ideas for that improvement - continuously. Or as Zuboff would say, return some 'know how' to staff so they are able to 'act-on'.

\section{ANZ BANK - A CASE STUDY}

In setting up a framework for staff diagnostic review groups (or Quality Circles) the focus is sometimes on 'trouble shooting', sometimes on customer service improvement and rather less of ten on influencing changes in management-staff relations. With the support and encouragement of top management, ANZ Bank* in Australia began its 'Customer Care' programme with an intentional focus on all three aspects. In other words, the programme was in one sense 'top-down' but it could also be called a 'bottom-up' programme. Culture changing effects were moving up the hierarchy, in terms of a more participative and open style of management, at the same time as 'customer first' messages were moving down the management chain to branch staff. In this way the interests of management and staff as legitimate stakeholders in the organisation moved with relative harmony of purpose; likewise the interests of shareholders as stakeholders were vested in the outcome.

* ANZ Bank is one of the four major retail banks operating Australia-wide, and is Australia's largest international bank. 
In building diagnostic groups in the Retail/Branch Banking Division at ANZ Bank, the intention was to remove any focus on hierarchies, that is to flatten hierarchies out. Groups are composed of people from all levels including Managers. 'Groupies', they call themselves. This flattening of hierarchy is confirmed by the absence of status titles in programme guides and in the programme itself. People seemed not to object to status as a surrogate for excellence - in fact they liked it. But they objected to status being used as a surrogate for power.

In ANZ groups, people talk about the concept of a 'natural' person, one who brings his or her whole self to the work. This is opposed to the role player, who brings to work only those personal values that 'fit' with what he or she feels comfortable; a secure fit within the organisational norms. This notion of the 'natural' person is a culture challenging proposition. It unfreezes personal constraint and opens up the possibility of self directed action, challenging the rigidity of the established culture.

Groups are set up in Regional workshops of 'volunteers', ie: people pre-selected, invited, who accept. There is no coercion. Participants are bonded into small groups of four, in a workshop process involving 16 to 20 people. Using group dynamics and small group bonding is the key developmental process. The small group bonding opens up the participants to a level of knowing about the group and themselves. This is a basis for self development and learning, a platform from which personal growth can be pursued by each participant, within his or her small group, during and after the workshop.

This is very necessary as a support element for the work task ahead, where each 'Groupie', must return to his or her branch and generate service quality changes, perhaps in the face of indifference, disbelief, or cynicism from some staff members. 
The aim of each workshop is to reach higher order personal values which motivate, those beyond 'fame', 'status' or cash 'rewards'. The commitment of groups is therefore focused on a superordinate goal, which is to put the 'Customer First' as a philosophy in practice. This is to be achieved after the workshop via practical service quality improvements.

The workshop process begins implicitly with personal 'value searching' because if the 'Customer First' mission is largely congruent with individual personal values, there is motiv(ation) for action. The group process opens up possibilities of new and more effective ways of going about work on a day by day basis, something of practical value in itself. This also is a motiv(ation) for action.

A further value motive is the prospect of personal growth, something that many people have not considered. So adding up the opportunities for self growth, practical and fulfilling approaches to work, and a focus on the customer, ANZ reaches out to every group member for their personal commitment to action.

Put another way, commitment to action starts with a focus on organisational goals which are congruent with personal values. A final incentive to action is a firm task deadline. This is set for two to three months out from the workshop date and agreed to by participants at their workshop.

It is a Diagnostic Review Process. There is a clear task focus in ANZ's approach and a specifically defined method. It consists of a set of methodological steps which enable service quality improvement, or opportunities for improvement, to be defined and examined on a fit for use basis.

Those who particularly value self development, usually enjoy the programme and processes so much that they want to contribute to the self development of others - 
another motiv(ation) for action. This would normally involve more workshops with a view to developing 'process' facilitation skills. The goal is that the person becomes capable of firstly planning and organising one complete cycle of the diagnostic review phase in their Region, and at a second level, assisting in the facilitation of a workshop, and at a third level, 'full licence' facilitation in any aspect of the programme.

The workshop programmes emphasise creative approaches to diagnosing critical service issues rather more than rational logical approaches. The intention is to challenge the existing cultural norms. Creative problem solving approaches also enable a sense of fun to be maintained in a working environment. This is the climate which permits innovation and a coming to terms with the desirability of change, and managing change.

In the workshops, permission is given to openly discuss what would otherwise in the banking culture be 'undiscussable', which leads to a developing sense of trust and commitment. The process is one of empowering people who, day by day, work in an environment where attitudes and actions are fairly prescribed.

The construction of networks of people involved in the diagnostic review process is focused on a District (Regional) level. People involved in the programme feel a bond of kinship, Australia wide. These network relationships are maintained by information sharing structures and by informal modes. There are network newsletters which are written and distributed on an Australia wide basis to group facilitators and on a Regional basis to group participants. These newsletters are the vehicles for explaining new techniques and information of value in the diagnostic review process. 
Networks are the vehicles for supporting and developing the practical service quality improvement which is the task goal of the programme. The 'self help' attitudes and experiences developed through creative problem solving techniques and the application of these to practical situations gives 'life' support to the network itself. In this way, the culture challenging effects associated with diagnostic review groups are not easily extinguished.

Every ANZ diagnostic 'Groupie' is conscious of the history of the programme, its origins, and his or her part in it. This is given tangible support at every opportunity, including well presented programme guides, network directories (names, addresses and phone numbers) and certificates of merit. There are formal 'presentation' ceremonies to Regional Managers for discussing results achieved in service quality improvement. Other channels are used for passing on service quality improvements which have application on an Australia wide basis.

There are also rituals which provide a sense of identity and continuity between past, present and future, like the 'Groupie handshake', a special way of sitting on chairs and 'magical mystery tours'!

There is a genuine sense of excitement and challenge about all this. Every diagnostic 'Groupie' senses that they are working 'against the grain'. They know that the organisation cannot change of itself and they accept some of the responsibility for initiating that change. The commitment to that responsibility is the beginning of personal development and the beginning of service quality improvement at grass roots level, and the role modelling of a new kind of banking behaviour which fits ANZ's strategic focus.

In his or her work, involving culture change, the ANZ diagnostic 'Groupie' is truly an invisible leader. As a change agent working toward practical improvement in 
service processes, the role as leader is quite visible. But it is the invisible aspect of leadership that counts in the long run. It is the kind of leadership that seeks out a more participative and less autocratic system of management. When 'Groupies' take practical action in terms of diagnostic work, this influences changes in their relationship with their manager, indeed the relationship of that manager and the rest of the branch staff.

The same invisible process begins at Regional level where the 'Groupie' facilitator through his or her task focused actions influences the relationship the Regional Manager has with his staff, and the relationship of the Regional Manager with his own branch managers.

Enthusiasm and task focus begin the diagnostic process. The practical outcome is the generation of ideas for improvement in service quality processes which in turn challenge the organisation towards changing the way things are done, the methods which are used, and the attitudes that go with it.

ANZ could never achieve a retail 'customer focused' transition from an operationally focused organisational culture with diagnostic review groups alone. What they have achieved are tangible results at the customer interface, and the value data is broadcast up and down the organisation. The outcome of this is that more opportunities for strategic interventions into the organisational culture open up for legitimate action, at all levels of the organisational hierarchy.

And so the process goes on, continuously. 


\section{MOTIVATION AND PERFORMANCE}

The experience at ANZ Bank over the last few years indicates that staff will do their job well if they know exactly what that job is... and if they are given the resources. That is, people work within systems because the very forces that provide the encasements - the 'prison' walls - also provide the structures that make them feel secure (Smith, 1982, p 12).

To step outside the performance system, that is to 'act-on' the system, requires a framework of another kind. Again, the experience of ANZ Bank provides some valuable insights here. Ideas for quality improvement are generated within staff 'networks' and at the same time decisions on quality improvements remain the province of management, according to hierarchical authority.

One alternative to the ANZ Bank approach would be to ask staff to perform better, to 'do their best' in achieving service quality improvements. Even if adequate training and encouragement is provided it is hard to avoid the conclusion that such methods are essentially 'coercive' because they ignore the range of service quality defects that exist within the performance system and its many processes.

If the call goes out to improve service quality by performing harder, staff might do it - for a while. Then they will try to subvert the system. It is embarrassing but true that many financial institutions draw up lists of service standards, indeed of ten with the agreement of staff, which include specific performance levels which cannot be consistently achieved. The case of telephones which ring, say, more than three times, illustrates this. If staff are expected to meet an 'impossible' standard they will try to do it for a while, but in the absence of any formal diagnostic approach to problem solving, they eventually will give up. Some people might then be tempted to reflect that 'this is the kind of staff problem that we see more and 
more today', and perhaps an observation of even more comfort would be 'we observe that our competitors are having similar problems'. The dilemma of the modern manager faced with 'service standards' is whether to drive workers harder at their assigned tasks, or whether to invite them to participate in generating ways of improving the performance system. The first way treats people as prisoners of the system and the second invites people to be agents of the system - a distinct and separate contribution for which their experience within the system makes them ideally suited.

'Customer Care' is a motivator when the quality improvement goal is seen to be worthy and valued, an opportunity to test one's personal limits, and in so doing contribute to the organisation's success. This three way motivational outlook provides opportunity for personal growth and the shift in management style from traditional/autocratic towards participative/collaborative.

The challenge for service quality management is that the production and delivery of services invariably occurs at the same time. There is little space for production inspection before delivery. Certainly during the 'front line' service encounter, the service is produced and delivered inter-actively from the customer's point of view. The focus of quality standard setting, therefore, must shift to the customer. Only the customers (or segmented groups of customers) can 'set' service standards. How the customers' standards are signalled and received becomes the central research issue.

\section{SERVICE QUALITY MANAGEMENT FEEDBACK AND MEASUREMENT SYSTEMS}

A step-by-step research approach is necessary, and an integrated framework is proposed in Chart 1. 
Key Contributor

Reward Systems

Slandards of

Service

Customer Complaints

Analysis

(Regional Level)

Customer Complaints

Diary

(Branch level)

Account Closure

Interviews

(Branch level)

Ex Customer Telephone Survey

(Regional level)

Staff Climate Monitor (quarterly)

Branch 'Silent Shopper (quarterly)

Branch Quality Maintenance Index (quarterly)

National Customer Service

Research Study

(annual)
Sarvice oullity Impravements

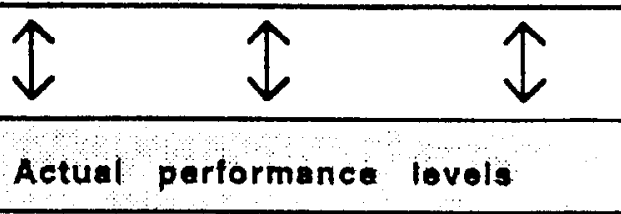

Sub standard service/diagnosis

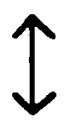

Sub standard service

Saving the relationship/diagnosis

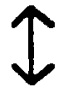

"What really went wrong"

- post-event diagnosis

attitudes
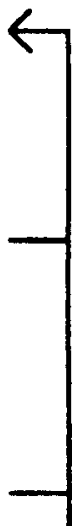

\section{- Iracking}


In turning the wheel of quality improvement, a beginning might be made at any step in the ladder but the process tends to move logically from a bench-mark customer service research study and up the ladder through various measurement and feedback systems. What is proposed is a mixture of hard and 'soft' measures. There can be no single assessment method for 'quality' and trying to find one would be to miss the point. Quality is exactly what each customer says it is, and it is only measurable when a mix of measurement instruments is used.

These service quality measures have five principal step components, as follows.

\section{- Customer Service Research Study}

This is a qualitative/quantitative empirical research measure which gives reliable tracking data, and valid input to the diagnostic review process. The 'solutions' generated by diagnosis will always be a mix of changes that cross departmental boundaries and branch network lines. Service 'problems' at branches are only partly resolved by action at the branch. Critical action in 'head office' policy and/or systems areas is usually overlooked unless a formal review process is established.

\section{- Branch Quality Maintenance Index}

This maintenance survey incorporates basic 'housekeeping criteria' (see some specimen items, Chart 2) and can be administered by branch staff or by district staff, or both. It is intended as part of an overall branch performance assessment. 


\section{- BRANCH MAINTENANCE (HOUSEKEEPING) CRITERIA}

In your assessment, are the following service issues up to satisfactory customer standard?

Please tick appropriate box in response to question.

If not applicable leave blank.

Yes

\section{OUTSIDE THE BRANCH}

- Pathways and/or gardens, branch front neat and tidy

- Windows and Door glass clear and clean

- Door handles and closers working and easy to open

- Door step easy to use and accessible

- Exterior lighting working and adequate

- Car parking available to customers (not occupied by staff)

- Visibility of signs (various views)

- Only essential decals, etc. (to be advised by Region)
No, but action is being taken
No

\section{AUTOMATIC TELLING MACHINE CASH DISPENSER, NIGHT SAFE}

- Lighting adequate

- Cleanliness of facia and screens (and lobby)

- No damaged parts (keyboards, security panel)

- Points of reference decal and advertising up to date

- Litter bin tidy

- Deposit envelopes available

- Keypad volume audible

- Key lock and trapdoor functioning

\section{"In House" ATM/CDU lobby}

- Air conditioning working

- Automatic doors working

- Customer entry/exit easy and sign posted

- Overhead camera - functioning

- readily viewable

- red light on

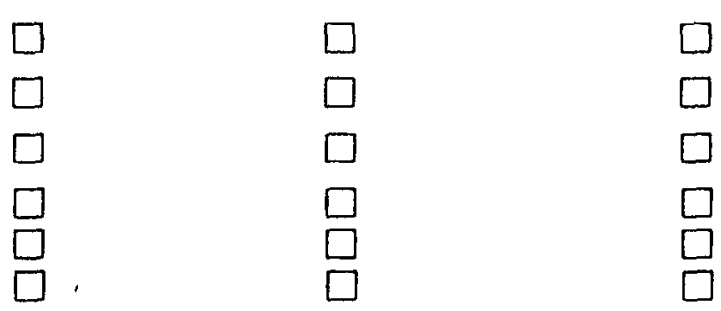

\begin{tabular}{|l|l|l|}
\hline & & \\
\hline
\end{tabular}




\section{- Branch Silent Shopper}

The 'silent shopper' is a survey measurement system based on the real shopping experience of customers. The measurement is done by skilled market researchers who are also genuine customers. This ensures that the shopping experience is as genuine as possible. The purpose of this measure is evaluative and diagnostic. Staff would be encouraged to 'act-on' the information received. That is, how might the work processes be improved?

\section{Staff Climate Monitor}

This survey is an empirical measure of branch/district staff opinion about quality of service at branches, and also the quality of work life. These two elements of course affect the quality of service experienced by the customer.

\section{Risk Point Analysis}

There are a range of 'sof $t$ ' research options here and all of them are intended to locate valid data about negative customer experiences. The fact that the data is not representative of the customer base as a whole is not the point. Any negative experience is variance within the system, and provides data for diagnosis and quality improvement.

Efforts to improve quality and service performance by better staff training may add cost, not value, unless the design of work, the environment in which service is delivered, and the processes involved are considered as a part of the diagnostic review. 
As people become involved in the diagnostic review work at 'grass roots' level, the challenge of spreading the philosophy of service takes form more and more at 'head office level'. What at first appears to be a simple process of 'getting staff involved' in fact involves researching out the critical service issues, introducing a diagnostic review process, reviewing quality improvement ideas, implementing system adjustments, reviewing training schedules and rewarding contributors to the quality improvement process (Chart 3 ).

\section{REWARDS AND MOTIVATION}

Rewards are intended to lead behaviour in certain directions, or to reinforce existing behaviour. Under what customer service conditions do rewards actually motivate staff? As work performance is subject to random effects within any performance system, staff of ten wonder whether 'trying harder' is worth the effort. Prisoners of the process! However, when the focus shifts to service quality management and customer service improvements, then the contribution of an idea becomes a voluntary act, uniquely outside the system, behaviour that should be reinforced.

Theories on rewards-motivation are anchored historically in the economic rationalism of the scientific management theorists and are of ten unhelpful. It is nonetheless true that top management can quickly get across their own priorities, values and assumptions by consistently linking rewards and punishments to the behaviour they want to encourage (Schein, 1985, p 234).

In other words, rather than directing discretionary remuneration to 'top performers' within the process, discretionary remuneration might be directed to performers who 'act-on' the process and suggest ways of improvement. In spite of the difficulty of judging the value of contributions, the right people do get rewarded for turning the wheel of quality improvement. 
Turning again to ANZ Bank, the formalised reward structure is called a 'Key Contributor Programme', an example of vanguard management thinking in the 'positioning' of rewards for quality improvement linked to their formal diagnostic review process.

If people work within the system, as prisoners of the process, but are enabled to become knowledgeable within it, they can contribute to quality improvement by acting on this know how, participating in the changes that affect their work life. And so the wheel of quality improvement keeps turning*.

August 1989

\footnotetext{
* 'Turning the wheel of quality improvement' is a term first used by Leone Trott, one of the original ANZ 'Groupies'.
} 


\section{CHART 3}

\section{TURNING THE WHEEL OF QUALITY IMPROVEMENT}

REVIEW

FEEDBACK AND MEASUREMENT

SYSTEMS

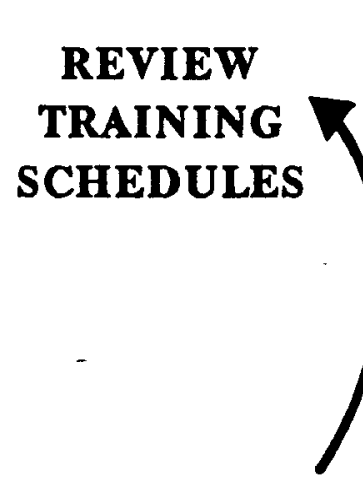

IMPROVEMENTS

TO SYSTEMS

INTRODUCED

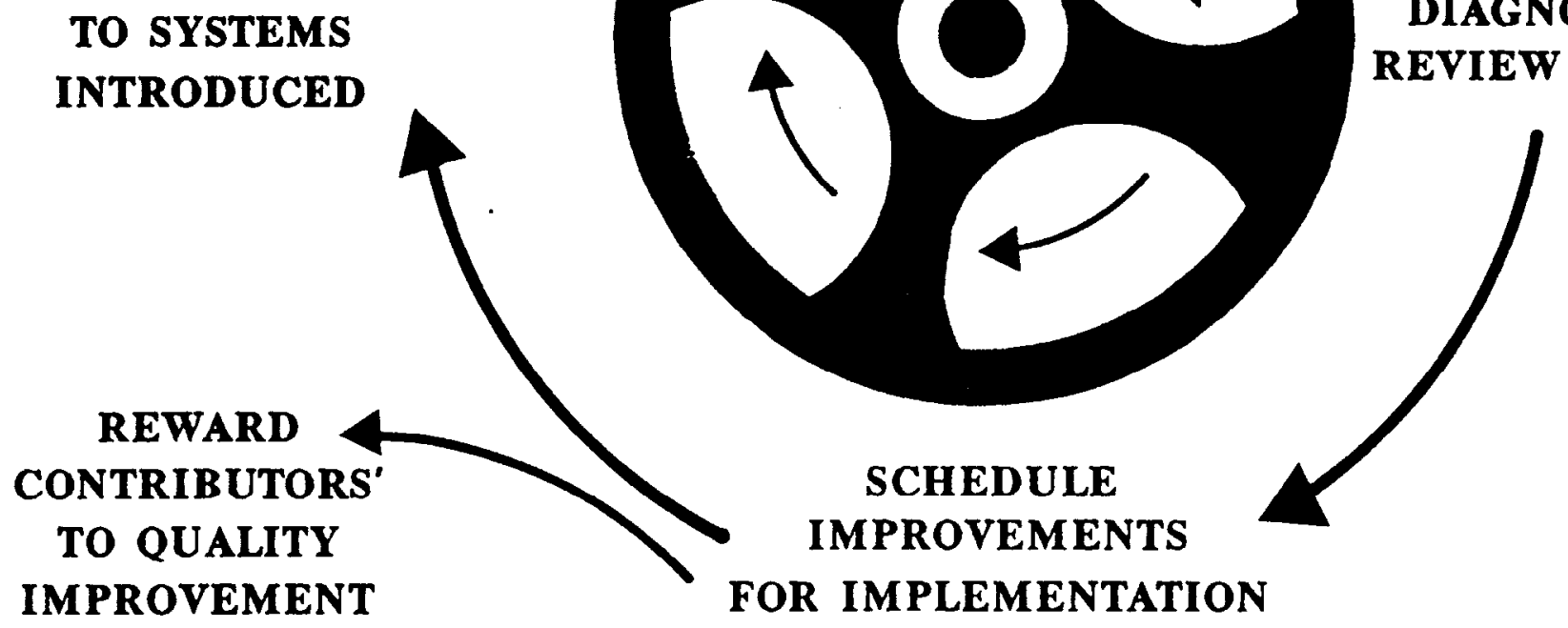

SERVICE EVALUATION

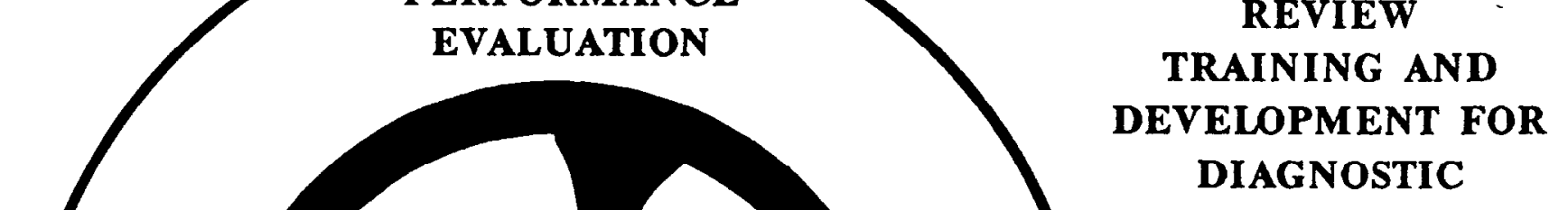

,

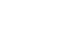

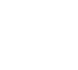
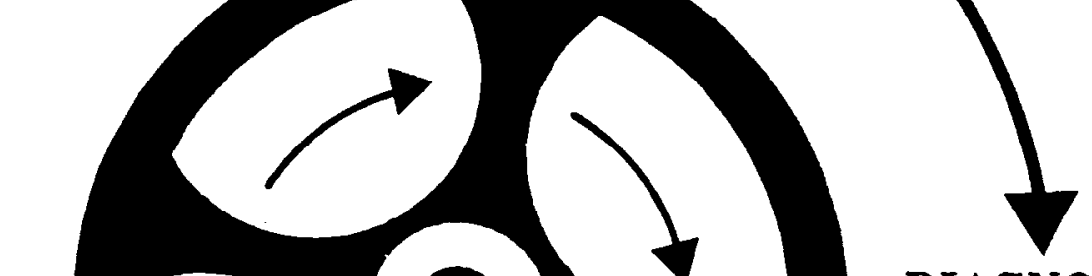$$
\text { SKILLS }
$$

DIAGNOSTIC REVIEW PHASE

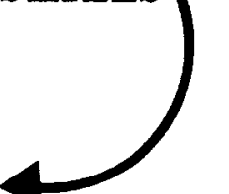




\section{REFERENCES}

Ballantyne, D, 'You Have to Twist the Kaleidoscope to See Things Clearly (Service Concepts and the Retail Banking Environment)' International Journal of Bank Marketing, Vol 5, No 1, 1987.

Berry, L L, BennetT, D R, and Brown, C W, Service Quality - A Profit Strategy for Financial Institutions, Dow Jones-Irwin, Homewood, 1989.

Deming, W E, Out of the Crisis, Massachusetts Institute of Technology, Cambridge, 1982.

JurAN, J M, and Gryne JR, F M, Quality Planning and Analysis, McGraw Hill, New York, 1980.

Kakabadse, A, Ludlow, R, and Vinnicombe, S, Working in Organisations, Penguin Business Books, London, 1988.

Peters, T, Thriving on Chaos - Hand Book for a Management Revolution, Pan Books, London, 1989.

Porter, M E, Competitive Advantage - Creating and Sustaining Performance, Free Press, 1985.

SCHEIN, E H, Organizational Culture and Leadership, London, Jossey-Bass, 1985.

Smith, K, Groups in Conflict (Prisons in Disguise), Dubuque, Kendall-Hunt, 1982.

Zuboff, S, In the Age of the Smart Machine, Basic Books, New York, 1988. 